\title{
Prosodie en motorische spraakstoornissen: een historisch overzicht
}

\author{
Frank R. Boutsen ${ }^{1}$, Justin D. Dvorak ${ }^{2}$ \\ ${ }^{1}$ Department of Communication Sciences and Disorders \\ ${ }^{2}$ Department of Biostatistics and Epidemiology \\ The University of Oklahoma Health Sciences Center, Oklahama City, OK, VS
}

\begin{abstract}
Samenvatting
Hoewel prosodie een prominente plaats inneemt in de classificatie en differentiaaldiagnose van motorische spraakstoornissen, hebben de theoretische kaders waarin prosodie en motorische spraakstoornissen zijn ontwikkeld een volledige integratie of samenvoeging van deze domeinen beperkt. De Mayo-classificatie blijft de gouden standaard, en onderscheidt de motorische spraakstoornissen in termen van hoorbare spraakafwijkingen waaronder prosodie. Hoewel kort uitgedaagd door een prosodische classificatie van de motorische spraakstoornissen (Kent en Rosenbek, 1983), duurde het tot de theoretische vooruitgang in normale prosodie uitmondde in een door de linguïstiek onderlegde objectieve meetmethode, voordat de akoestische benadering van het meten van prosodie een echt potentieel toonde om de audio-perceptuele benadering aan te vullen voor het in kaart brengen van het prosodische landschap in motorische spraakstoornissen.
\end{abstract}

\section{Summary}

Even though prosody figures prominently in the classification and differential diagnosis of motor speech disorders, the theoretical frame works in which prosody and motor speech disorders have evolved have limited a full integration or merging of these domains. The Mayo Classification continues to be the gold standard and differentiates the motor speech disorders in terms of audible speech deviations including prosody. While briefly challenged by a prosodic classification of the motor speech disorders (Kent and Rosenbek, 1983), it was not until theoretical advances in normal prosody culminated in an objective measurement approach that was informed by linguistics that the acoustic approach to prosody measurement showed real potential to complement the audio-perceptual approach to map the prosodic landscape in motor speech disorders.

Correspondentieadres: Frank Boutsen, Ph.D., Department of Communication Sciences and Disorders, The University of Oklahoma Health Sciences Center, 1200 N. Stonewall, AHB 3079, Oklahoma City, Oklahoma, 73117, VS

E-mail: Frank-Boutsen@ouhsc.edu 


\section{Introductie}

In een tijdperk waarin de termen spraak en taal door elkaar werden gebruikt, en Broca en Wernicke's constructies van 'afemie' en 'afasie-symptoomcomplex' ogenschijnlijk harmonieuze verzoening vonden in de localisatietheorieën over taal, brak Kussmaul (1877) met deze traditie door de stelling te verdedigen dat spraak niet beperkt was tot een cerebrale convolutie. Hij maakte ook een duidelijk onderscheid tussen de neurologische aandoeningen van spraak en taal. In wat mogelijk de eerste classificatie van neurogene communicatiestoornissen is, definieerde hij, losstaande van afasie, een groep articulatiestoornissen die te wijten waren aan organische of psychische stoornissen van het centrale zenuwstelsel (central nervous system; CNS). Hij kan gecrediteerd worden met het bedenken van de term 'dysartrie', waarin hij articulatiestoornissen onderscheidde van dyslalieën die het gevolg waren van perifere laesies en / of misvormingen van de articulatoren of de craniale zenuwen (Grewel, 1957). Kussmaul's classificatie, hoewel provocerend voor zijn tijd, deed niet veel meer dan het concept van dysartrie af te bakenen, door het te beperken tot het CNS, losstaande van taal en functionele / organische spraakstoornissen (Boutsen, 2006).

\section{Neurologische classificaties van dysartrie}

Rond de eeuwwisseling werden laesies in het centrale zenuwstelsel voorgesteld gevolg te hebben voor het (on)vermogen tot articuleren, evenals het idee dat gradaties van herstel geassocieerd waren met verschillende klinische spraakgebreken. Pierre Marie (1906) beweerde bijvoorbeeld dat het anatomische substraat voor 'zuivere anartie' in een 'lenticulaire zone' lag van de frontale cortex en subcortex tussen het hoofd van de caudate en het posterieure einde van de lenticulaire nucleus. Marie \& Foix (1917) maakten later onderscheid op basis van de mate van herstel van de spraakstoornis. Ze gebruikten de term 'anartrische syndromen' voor herstelde gevallen met spraakstoornissen die in de meeste ernstige voorbeelden zich presenteerden met een aanvankelijk volledig onvermogen om woorden te uiten. Ze gebruikten het label 'dysartrie' voor gevallen waarin bij herstel woorden verkeerd werden uitgesproken of zinnen niet vaardig geuit konden worden. Het is duidelijk dat dit onderscheid de voorbode was van de moderne indeling van motorische spraakstoornissen als bestaande uit 'dysartrieën en apraxie van spraak'.

In omstreeks de volgende twee decennia begonnen meer verfijnde neurologische classificatieschema's een koppeling vast te stellen tussen het nog vrij amorfe dysartrie symptoomcomplex en etiologieën die waren gebonden binnen niveaus / componenten van het centrale zenuwstelsel. Zentay (1937), Froeshels (1943) en Luschsinger \& Arnold (1949) classificeerden bijvoorbeeld dysartrie als afkomstig van vier niveaus binnen het centrale zenuwstelsel (cortico-bulbair, cortico-strio-pallido-rubro-bulbair, fronto-pontine, en cerebellaire niveaus). Groeiende aandacht voor bewegingsstoornissen en spraakprocessen anders dan 'articulatie', tezamen met een bredere reeks 'dysartrische' symptomen die een theoretische dekking nodig hadden, zorgde snel voor een verfijning en uitbreiding van de 4-niveaus classificatieschema's om zo ook het perifere zenuwstelsel (peripheral nervous system; PNS) te omvatten. 


\section{Paradigmatische verschuiving in de conceptualisatie van dysartrie rond de jaren 50 en 60}

Interessant is dat er twee belangrijke paradigmatische verschuivingen plaatsvonden in de jaren 50 en 60. Eén werd geïntroduceerd door Monrad-Krohn (1948) toen hij het klinisch onderzoek naar prosodie initieerde na het verzorgen van een Noorse vrouw die in de Tweede Wereldoorlog verwondingen door granaatscherven opliep aan het links-frontale hersengebied, en afasie van Broca veroorzaakte (Ross, Shayya, \& Rousseau, 2013). Hoewel de vrouw uitstekend herstelde, klonk haar spraak niet langer als die van een geboren Noorse. Hoewel de melodie van haar spraak behouden bleef, zoals bleek uit haar vermogen om te zingen, te intoneren, en emoties te uiten, had ze een verkeerde toepassing van klemtonen en pauzes, waardoor haar spraak een vreemd accent kreeg (Ross et al., 2013). Gebaseerd op deze en andere patiënten verdeelde Monrad-Krohn (1963) 'prosodie' in vier hoofdcomponenten: intrinsieke, intellectuele, emotionele, en ongearticuleerde prosodie. Intrinsieke prosodie verbetert en verduidelijkt de talige aspecten van een taal door zorgvuldig gebruik van toonhoogte, intonatie, duur, pauzes en beklemtoning. Prosodische beklemtoning en pauzeren helpen bij potentieel dubbelzinnige syntaxis door het definiëren van frasale grenzen. Intellectuele prosodie geeft de houding van de spreker weer ten opzichte van de inhoud die wordt medegedeeld. De spreker kan bijvoorbeeld sentimenten overbrengen die tegengesteld zijn aan wat er wordt gezegd, zoals "de lezing was erg interessant" (saai). Emotionele prosodie zorgt voor primaire soorten van spraakemoties, zoals geluk, verdriet, angst en woede. Ongearticuleerde prosodie is het gebruik van bepaalde paralinguïstische non-verbale elementen, zoals gegrom en zuchten, teneinde het discours te flatteren (Boutsen, 2010).

Fundamenteel voor een andere belangrijke paradigmaverschuiving waren twee publicaties, één door Grewel (1957) en de andere door Peacher (1950), zie Boutsen (2006). Peacher, beïnvloed door Monrad-Krohn's werk, voegde ritme (of zelfs prosodie) toe aan de spraakprocessen van articulatie, fonatie, resonantie en ademhaling in een manuscript getiteld "The etiology and differential classification of dysarthria". De titel van deze publicatie is veelzeggend omdat het het (moderne) tijdperk van de geclassificeerde dysartrieën (meervoud) introduceert. Peacher besprak voor het eerst de rol van spraakprocessen in dysartrie en gaf ritme een overkoepelende rol daarin. Hij betoogde het belang van ritme in het licht van onderzoek dat de perifere afhankelijkheid van ademhaling aantoont, de afhankelijkheid van auditieve feedback (zoals aangetoond door het onvermogen bij doven om ritme te ontwikkelen), maar ook de relatie met ontogenetische factoren zoals taalontwikkeling en op een nog hoger niveau emotionele en intellectuele factoren. Grewel kan worden gecrediteerd met het definiëren van praxis en uitvoering in spraak, samen met het koppelen van motorstoornissen aan de dysartrieën. Uitvoering werd beschreven als de afwikkeling van een serie van reflexen, waarvan werd gedacht dat deze afhankelijk was van intacte gevoeligheid alsmede coördinatie van ademhaling, fonatie, en articulatie. Langs deze lijnen definieerden ze spraakapraxie als een subtype, zij het in de marge, van dysartrie (Boutsen, 2006).

Peacher en Grewel beweerden beiden dat een neurologisch perspectief op dysartrie dia- 
PROSODIE EN MOTORISCHE SPRAAKSTOORNISSEN: HISTORISCH OVERZICHT 101

gnostische kracht en therapeutische relevantie ontbeerde als het niet ook werd aangevuld met een gedetailleerde spraakanalyse. In dit verband stelden zij enkele procedurele richtlijnen voor de diagnose van dysartrie voor, en gaven een eerste brede beschrijving van de spraaksymptomen in de verschillende dysartrie-typen. Toch was Peacher (1950) van mening dat beschrijvingen van dysartrische spraak subjectief en op zijn best impressionistisch waren, en riep op tot een herrijzenis van het hele veld met behulp van de grondbeginselen afkomstig van de experimentele fonetiek en spraakpathologie (Boutsen, 2010).

Hoewel Darley Aronson \& Brown (1969a; 1969b) nog geen experimentele methode toepasten, gaven ze gehoor aan de oproep tot het systematisch bestuderen van de dysartrieën. In wat gekenmerkt kan worden als de eerste systematische en uitgebreide studie van de hoorbare kenmerken van de dysartrie-typen, evalueerden zij spraak afkomstig van leesfragmenten van 212 patiënten met dysartrie. De patiënten hadden een neurologische diagnose die viel in een van de zeven categorieën: pseudo-bulbaire verlamming, bulbaire verlamming, amyotrofische laterale sclerose, cerebellaire laesies, parkinsonisme, dystonie en choreoathetose. Deze neurologische aandoeningen waren een aannemelijke keuze, omdat zij het onderwerp waren van eerdere uiteenlopende dysartrie-onderzoeken. Terwijl ze naar de banden luisterden, probeerden Darley en zijn collega's de verschillende verschijnselen van de dysartrieën vast te leggen, niet binnen neuroanatomische niveaus zoals eerder was gedaan, maar binnen het hoorbare domein. Met het oog op dit doel conceptualiseerden zij een reeks spraak- en stemdimensies om de spraakfragmenten te beoordelen. Uiteindelijk legden Darley, Aronson \& Brown 38 dimensies vast in zeven hoofdcategorieën. Deze omvatten toonhoogte (niveau, onderbrekingen, tremor, of mono), luidheid (niveau, verval, wisselend, extreem gevarieerd, of mono), stemkwaliteit (harde / natte heesheid, continue / voorbijgaand ademen, gespannen stem, hypo / hypernasaliteit, en nasale emissie), hoorbare aspecten van de ademhaling (geforceerde inademing of uitademing, hoorbare aanblazing, gegrom aan het einde van de expiratie), prosodie (snelheid, korte frases, verhoogde algehele / segmentale snelheid, variabele snelheid, verminderde / excessieve beklemtoning, stiltes, korte spreekversnellingen), en articulatie (onnauwkeurige consonanten, klinkerdistorsie, verlengde / herhaalde fonemen, onregelmatige articulatorische onderbrekingen). Daarnaast werden spraakfragmenten beoordeeld op basis van twee globale dimensies: verstaanbaarheid en bizarheid (Boutsen, 2006).

De resultaten van het onderzoek van Darley et al. (1969a) lieten zien dat onnauwkeurige medeklinkers, afwijkingen in toonhoogte en snelheid, monotoonheid, monoluidheid, en hypernasaliteit prominent aanwezig waren in de groepen. Interessant is dat consonanten kwetsbaarder bleken dan klinkers. De resultaten toonden verder aan dat voor een bepaalde neurologische aandoening niet alleen een afzonderlijke dimensie uniek bleek te zijn, maar ook de co-incidentie van verschillende dimensies was verschillend. De vijf fundamentele 'perceptuele' patronen die aldus gevonden werden kregen fysiologische labels en werden slappe, spastische, ataxische, hypokinetische, en hyperkinetische dysartrie genoemd. Deze labeling, die doet denken aan die gevormd door het neurologische perspectief op dysartrie, vond een verdere uitwerking en onderbouwing in Darley et al., (1969b). In Darley et al. 
(1969b) deelden ze de overeenkomende dimensies (clusters) in aan de hand van neuromusculaire gebreken. Deze zijn samengevat in Tabel 1.

Tabel 1: Clusters van dysartrische spraakdimensies en voorgestelde bijbehorende neuromusculaire gebreken (Darley et al., 1969b).

\begin{tabular}{ll}
\hline Cluster & Afwijking \\
\hline Onnauwkeurige articulatie & Onnauwkeurige richting van bewegingen \\
Prosodische overtolligheid & Geen directe fysiologische betrokkenheid \\
Prosodisch tekort & Beperkt bewegingsbereik \\
$\begin{array}{l}\text { Articulatorische / resonantorische } \\
\text { incompetentie }\end{array}$ & $\begin{array}{l}\text { Verzwakte kracht van spiercontracties en } \\
\text { beperkt bewegingsbereik }\end{array}$ \\
$\begin{array}{l}\text { Fonatorische stenose } \\
\text { Fonatorische / resonantorische } \\
\text { incompetentie Anname in contractiesterkte } \\
\text { Fonatorische-prosodisch tekort }\end{array}$ & Ongebalanceerde hypertonus \\
\hline
\end{tabular}

Zoals kan worden gezien in Tabel 1, legden Darley et al. (1969b) een bewegingsgebrek vast als basis voor elke cluster, behalve voor prosodische overtolligheid. Later, in hun nu klassieke monografie, gingen Darley et al. (1975) verder met het definiëren van de dysartrieën en apraxie van spraak binnen het concept van motorische spraakstoornissen (Boutsen, 2010). In tegenstelling tot Peacher en Grewel eerder, maakten ze een duidelijke scheiding tussen apraxie van spraak en dysartrie. Spraakapraxie betrof in hun ogen een gebrek in een van de drie hiërarchisch georganiseerde conceptuele motorstadia (processen), te weten formulering van het doel, en het plannen en programmeren van bewegingen. Fysiologisch en anatomisch werden voornoemde stadia beschouwd als gescheiden van de uitvoering, een motor stadium dat uniek verbonden werd met dysartrie. De eerstgenoemde processen werden, met uitzondering van het globale corticale proces van doelformulering, beschouwd als links lateraal en hadden geen directe neuromusculaire betrokkenheid of een prosodisch gevolg. Aan de andere kant omvatten dysartrische processen motorische executie met uitsluiting van sensorische processen en werden gerelegeerd naar hogere motorische neuronen (bilateraal), tezamen met de extrapyramidale, cerebellaire en lagere motorische neuronen (Boutsen, 2006)

\section{Centrale opvattingen van prosodie in de jaren vijftig en zestig}

Terwijl in de vroege dertiger jaren over het algemeen gedacht werd dat 'normale' prosodie secundaire aanpassingen van segmentale kenmerken betekende (Bloomfield, 1935), gingen vroege verkenningen in het rijk van prosody door Jakobson, (1931) en Trubetzkoy (1939) over de fonologische status van prosodie en de dimensies van lengte, toonhoogte en accent 
(ritme), en hun plaats langs paradigmatisch-syntagmatische lijnen in het bijzonder. In dit opzicht resulteerde de discussie over lengte in wat bekend is geworden als het probleem van de 'kwantiteit' (Fox, 2002). Trubetzkoy (1939) merkte op dat alle fonemen, wanneer ze bestaan, een bepaalde tijd innemen. Daardoor zou in zijn visie het bezit van een fundamentele eenheid van tijd door een foneem op zichzelf niet fonologisch relevant kunnen zijn, en dus tijd een irrelevante fonologische eigenschap maken die verder niet kan worden gebruikt. Het is duidelijk dat deze conclusie problematisch was, en dat de fonologische versus prosodische status van lengte nooit volledig is opgelost.

Het is in de jaren vijftig dat Jakobson, Fant en Halle (1951) de prosodische kenmerken van toonhoogte, klemtoon en duur volledig onderscheiden van de onderscheidende kenmerken 'inherent' (mijn cursief) in de segmentale consonanten en klinkers. Ze benoemen drie soorten prosodische kenmerken: kracht, kwantiteit en toon, corresponderend met de sensorische attributen van stemluidheid, relatieve subjectieve duur en stem-toonhoogte. De dichtstbijzijnde fysieke correlaten zijn, in dezelfde volgorde, intensiteit, tijdspatroon en stemfrequentie (Kent \& Rosenbek, 1983). Voor Jakobson et al., (1951) zijn prosodische kenmerken syntagmatisch, d.w.z. coderende suprasegmentele veranderingen gedurende de positie (of tijd) binnen de uiting. Trubetzkoy (1939) introduceerde de visie van prosodie als de organisatiestructuur van spraak.

In dit tijdperk vindt ook de experimentele fonetiek zijn prosodische basis. Fry (1955) en Bolinger (1958) gebruiken grondtoonfrequentie (F0) als een belangrijk correlaat van woordklemtoon en frasale prominentie. Bolinger (1958) betoogt vanuit kunstmatige en natuurlijke spraakdata dat de primaire cue van wat klemtoon wordt genoemd in feite toonhoogte prominentie is, en dat intensiteit verwaarloosbaar is als een kwalitatieve en een bepalende factor in klemtoon. Bolinger (1958) is van mening dat het beter is om te spreken van toonhoogteaccent en de term klemtoon over te laten aan het domein van woordbeklemtoning. In dit laatstgenoemde domein stelt hij dat een mogelijke soort van fonemische stress een "potentieel" (mijn aanhalingstekens) is voor toonhoogteaccent. Hij stelt verder dat toonhoogteaccenten niet slechts unidirectioneel zijn, maar ook omhoog, omlaag, of niet van richting kunnen veranderen, en daardoor verschillende woorden in een zin kunnen beaccentueren. Hij geeft de volgende voorbeelden om dit punt te maken:

(1) 100 Wouldn't it be easier to 120 wait?

(2) 100 Wouldn't it be 120 easier to wait?

(3) 100 Wouldn't it be easier 120 to 100 wait?
Toonhoogte beweging

Omhoog tot wait

Vlak tot easier

Omlaag tot wait
Waargenomen klemtoon

wait

$\underline{\text { easier }}$

$\underline{\text { wait }}$

Ladefoged (Ladefoged \& McKinny, 1963; Ladefoged, 1967) en Lieberman (1967) kunnen worden gecrediteerd met het toevoegen van een fysiologisch perspectief aan de analyse van toonhoogte gedurende een uiting. Het werk van Lieberman was fundamenteel voor het concept van ademgroepen (Lieberman, 1967). Ladefoged onderzocht de bijdragen van subglottale druk en laryngeale spierspanning aan toonhoogte. Hij onderzocht dit in verklarende en 
vragende uitingen die woorden bevatten die contrasterend waren in termen van talige beklemtoning. Hij gebruikte de zinnen zoals (onderstreping geeft klemtoon aan):

(1) /That's a digest/ versus /That's a digest?/

(2) /He didn't digest/ versus /He didn't digest?/

Het is bewezen dat in verklarende zinnen subglottale druk een goede voorspellende is van de stijging, plateau, en daling van toonhoogte, maar dat bij vragende zinnen een toonhoogtestijging plaatsvindt terwijl de subglottale druk naar beneden gaat. De F0-stijging aan het einde van vragende zinnen kon daarom niet worden toegeschreven aan subglottale druk. Hij concludeerde dat de F0-stijging het gevolg is van toegenomen spierspanning veroorzaakt door intrinsieke laryngeale spieractiviteit. Wat betreft de talige beklemtoning gaf hij een verhoogde toonhoogte als een belangrijke cue aan, maar wijst ook op het belang van duur en intensiteit. zoals anderen voor hem hadden gedaan. Fry (1955) concludeerde in een eerder onderzoek dat zowel duur als intensiteit correlaten waren van talige beklemtoning, maar dat duur belangrijker was. Het kan gesteld worden dat tegen het einde van de jaren zestig een samensmelting van akoestiek met fysiologie plaatsvindt die samenvalt met de ademgroep, weliswaar niet zonder veel debat (zie Vanderslice, 1969). Op dat moment omringt een soortgelijke controverse ook het concept van ritme, de taalkundige oorsprong ervan, en of het bestaat in spraakproductie, in spraakperceptie, of in beide. Deze discussie komt in een uitgebreider debat naar voren over de vraag of talen kunnen worden ingedeeld in termen van ritme of prosodie. Abercrombie (1967) volgt bijvoorbeeld Pike (1945) bij het beschrijven van het spraakritme in termen van de intervallen tussen de aanzetten van linguïstische eenheden - syllaben, moras of voeten (Tilsen en Johnson, 2008). Hij beschrijft echter ook het begrip ritme als isochronie wanneer hij twee ritmische klassen, toonhoogteen syllabe-timing herkende, en stelde voor dat alle talen tot een van beide klassen behoren. Volgens Abercrombie wordt een of ander taalkundig bestanddeel in het spraaksignaal samen gepland met temporele periodiciteit. Het niet observeren of waarnemen van deze periodiciteit wordt toegeschreven aan 'ruis'-factoren, waarvan interessant genoeg de spraakhandeling er een is (Abercrombie, 1967).

\section{Motorische spraakstoornissen na Darley - heden: hoewel kort uitgedaagd consolideren de Mayo Classification en de audio- perceptuele methode als de gouden standaard}

In de vroege jaren tachtig werd de Mayo Classification aanpak, aangehangen door Darley et al. (1975), kort uitgedaagd door Kent \& Rosenbek (1983). Deze aanpak had tegen die tijd zijn belangrijkste grondbeginselen goed gevestigd: 1) De dysartrieën en spraakapraxie definiëren de motorische spraakstoornissen, en kunnen onderscheiden worden van de neurologische spraakstoornissen. 2) Spraakapraxie is een motorische programmerings / planningsstoornis, terwijl de dysartrieën stoornissen van bewegingsuitvoering zijn (slapheid, spastici- 
teit, ataxie, hyperkinesie, hypokinesie). 3) Spraakapriaxie wordt gekenmerkt door inconsistente articulatiefouten inclusief fouten in sequentiëring, maar prosodie kan normaal zijn. 4) De differentiaaldiagnose van de motorische spraakstoornissen kan en moet worden bereikt volgens de audio-perceptuele methode.

Kent \& Rosenbek (1983) boden wat zij beweerden de eerste akoestische analyse van twee soorten prosodische abnormaliteit beschreven door Monrad Krohn (1963), d.w.z. dysprosodie en aprosodie. Daarbij volgen ze niet alleen een prosodische classificatie, maar stellen ze ook een akoestische methode voor om hun motorische spraakstoornissen te analyseren en te classificeren. Wat betreft hun definitie van prosodie, terwijl ze zich over het algemeen houden aan het gezichtspunt van Jacobson et al., (1951), wijken ze ook van hen af en volgen Gibson (1976) die stelt dat suprasegmentaal en prosodisch geen synoniemen zijn. Zij zijn het met Gibson eens, die opmerkt dat als aan de ene kant de term 'suprasegmentaal' een segmentale of fonemische analyse vooronderstelt, en suprasegmentele kenmerken worden beschreven als een soort residue, dan zou het onjuist worden om ze tegelijkertijd te definiëren zonder rekening te houden met een segmentale organisatie. Kent \& Rosenbek (1983) lenen verder van Gibbon's (1976) denken, wanneer ze stellen dat de systemen die mogelijk onder prosodische analyse vallen, intonatie, klankaccent, toonhoogte, pauzes, ritme en relatieve duur omvatten (Gibbon, 1976). Ze stellen voor dat deze systemen akoestisch benaderd kunnen worden door het meten van het temporele patroon, de intensiteit en de F0 contour. In overeenstemming met Kent en Netsel (1975) merken ze bijvoorbeeld op dat de perceptuele spraakafwijking van prosodische overtolligheid een vervorming van het tijdspatroon van spraak kan zijn. Dit patroon wordt gekenmerkt door verlenging van normaal gereduceerde syllaben en het optreden van atypische pauzes of inter-syllabische onderbrekingen. Ze beschrijven 'scanderende' spraak in akoestische termen zoals ze het zien als zijnde gekenmerkt door beperkte variatie in syllabeduur, de aanwezigheid van brede en bijna regelmatige afstand tussen syllabische kernen en een over het algemeen vlakke F0 contour over de eerste vijf syllaben. Kent \& Rosenbek (1983) beweren verder dat de afwijkende perceptuele dimensies geassocieerd met ataxische dysartrie, spraakapraxie en hypokinetische dysartrie (zoals beschreven door Darley et al., 1969a, b) en aprosodie (zoals beschreven door Ross \& Mesulam, 1978 en Sackeim \& Gur, 1978) zich meer vormen naar dysprosodie (ataxische dysartrie, spraakapraxie) en aprosodie (hypokinetische en rechterhemisfeer-dysartrie). Daarbij wijken ze af van Darley et al. omdat ze wijzen op akoestische overlap in plaats van wat de motorische spraakstoornissen perceptueel scheidt.

Toch is de Mayo Classification al bijna 50 jaar de gouden standaard in motorische spraakstoornissen. Duffy's (1995) recente update van de theorie voegde unilaterale upper motor neuron dysartrie toe aan de classificatie, maar was verder trouw aan de grondbeginselen van Darley et al. (1969 a, b; 1975). Zoals Darley et al. (1969 a, b; 1975), onderstreept Duffy de noodzaak van een strikte naleving van een 'perceptuele' routekaart die de classificatie van dysartrie begeleidt, en de toepassing van een pure motorische interpretatie van de neurofysiologische onderbouwing in overeenstemming met een drietrapsmodel van spraakproductie, te weten de cognitief-taalkundige, programmings-, en executiefasen. 
In de afgelopen twee decennia hebben Van der Merwe (1997), McNeil (1997), en Boutsen (Boutsen \& Christman, 2002; Boutsen 2003; Boutsen, 2004) enkele basisprincipes van de Mayo Classification betwist. In overeenstemming met onderzoek dat aantoont dat het cerebellum en de basale ganglia betrokken zijn bij cognitieve, linguïstische en motorische aspecten van spraak, beweren ze dat een scherp onderscheid tussen spraakapraxie en dysartrie niet houdbaar is, zelfs niet in neurofysiologische termen. Daarnaast, de sensorimotorische aard van spraak benadrukkend, hebben ze een cruciale rol toebedeeld aan gehoor en proprioceptie bij spraakstoornissen, en betoogden dat contextspecificiteit een rol speelt bij motorische spraakstoornissen. Boutsen $(2003 ; 2008)$ betoogde in dit verband dat spraakcontexten wisselend inspelen op prosodische doelen die intrinsiek of extrinsiek zijn voor de taal. Toch, terwijl deze theorie de focus van motorische spraakstoornissen terug bracht naar prosodie, kon er geen alternatief akoestisch-prosodisch perspectief op de perceptuele auditieve methode uit worden afgeleid, en was nog steeds ontbrekende.

\section{Ontwikkelingen op het gebied van prosodie: na cruciale ver- schuivingen in de jaren zestig tot heden}

Het is redelijk om te stellen dat, terwijl de perceptueel-akoestische methode de status-quo is gebleven in motorische spraakstoornissen, pogingen om prosodie of aspecten daarvan te meten zich aanzienlijk ontwikkelden. Interessant is dat de impulsen rond deze meetmethoden evolueerden rond raamwerken (spraakwetenschap, fonologie) of debatten (klemtoonof syllabe-getimede taaltypen) die niet relevant leken te zijn voor een toepassing in motorische spraakstoornissen. Een extra stimulans was afkomstig van een uitdaging om een oplossing te vinden voor wat kan genoemd worden als het probleem van de afwezigheid van referentie, dat vooral relevant is in de prosodie $(\mathrm{Xu}, 2011)$. Vanwege de grotendeels afwezigheid van orthografische representaties (afgezien van interpunctie) om prosodie weer te geven, is er weinig om op terug te vallen als het gaat om het identificeren van de prosodische eenheden, hetzij in termen van hun temporele locatie, bereik, fonetisch eigenschappen of communicatieve functie $(\mathrm{Xu}, 2011)$.

\section{Op fonologie gebaseerde benaderingen: eenheden en de opkomst van nieuwe metrieken}

Het kan gezegd worden dat het probleem van de afwezigheid van referentie in zoverre is aangepakt dat er eenheden zijn gedefinieerd in fonologische benaderingen van prosodie, zoals die zijn voorgesteld door Pierehumbert (1980) en Ladd (1996) (intonationale benadering) aan de ene kant, en door Selkirk (1981), Nespor \& Vogel (1986) en Prince \& Smolensky (1993) aan de andere (op syntaxis gebaseerde benadering). Schattuck-Hufnagel \& Turk (1996) en Sun-ah (2007) hebben de prosodische eenheden / hiërarchieën die in beide benaderingen zijn ingedeeld uit de literatuur samengevat, en zijn weergegeven in Tabel 2.

Zoals te zien overlappen de voorgestelde prosodische eenheden / hiërarchieën elkaar 
PROSODIE EN MOTORISCHE SPRAAKSTOORNISSEN: HISTORISCH OVERZICHT 107

Tabel 2: Eenheden in syntaxis- en intonatie-gebaseerde benaderingen van prosodie (Jun, 2007; Turk \& Shattuck-Hufnagel, 1996).

\begin{tabular}{lll}
\hline Eenheden & Syntaxis-gebaseerd & Intonatie-gebaseerd \\
\hline & Nespor \& Vogel (1986), Selkirk (1978), & Pierrehumbert \& Beckman (1988) \\
& Hayes (1989) & \\
\hline Uiting & Geen equivalent & Geen equivalent \\
Intonatiefrase & Intonatiefrase & Volledige intonatiefrase \\
Fonologische frase & Grote frase & Tussenliggende frase \\
& Kleine frase & Accentuele frase \\
Prosodisch woord & Prosodisch woord & - \\
Voet & Voet (jambe, trochee, spondee) & \\
Syllabe & Syllabe & Mora \\
\hline
\end{tabular}

aanzienlijk, terwijl de onderliggende voorspellers, d.w.z. syntaxis of intonatie deze benaderingen onderscheiden (zie Shattuck-Hufnagel \& Turk (1997) voor een discussie).

Verder kan worden gezegd dat de intonatiebenaderingen misschien de grotere verschuiving in de fonologie introduceren, omdat zij intonatie net zo goed als een onderdeel van fonologie aanmerken zoals als het foneem dat eens was. Hoewel articulatorische en akoestischperceptuele kenmerken zeker gemodelleerd werden in fonologie, plaatst intonatie-fonologie F0 en intonatie voorop in het gebied van fonologie. Specifiek onderscheidt de intonatiebenadering met name toonhoogte F0 van intonatie, en houdt aan dat talen F0 lexicaal of niet-lexicaal gebruiken (Hirst \& Di Cristo, 1998). Het lexicaal gebruik van toonhoogte wordt toon genoemd (verandering in F0 verandert betekenis in toontalen) en toonhoogte accentuering (woordbeklemtoning in Engels). Niet-lexicaal gebruik omvat post- (of supra) lexicale toepassingen van toonhoogte dat in het algemeen intonatie genoemd wordt, terwijl paralinguïstisch gebruik veranderingen in toonhoogte omvat om emotie en zelfs sarcasme te tonen (Hirst \& Di Cristo, 1998; Avaniti \& Fletcher, 2007). Binnen dit raamwerk wordt intonatie opgevat als het taalkundig gecontroleerde en pragmatisch betekenisvolle gebruik van F0 dat hele uitingen omvat (Arvaniti \& Fletcher, 2007; Xu, 2015). De primitieven van intonatie zijn tonen of tonale doelen: laag $(\mathrm{L})$ en hoog $(\mathrm{H})$, terwijl F0 contouren vaak worden beschouwd als categorische gestalt-achtige vormen die variatie in F0 detail mogelijk maken (Arvaniti, 2011).

In auto-segmentale metrische (AM) modellen, ook bekend als het Pierrehumbert-model (Pierrehumbert, 1980; Pierrehumbert \& Beckman, 1988), en het input process output (IPO-) model ('t Hart et al., 1990) worden gesequenceerde tonale doelen (toonhoogtebewegingen) autosegmenten (bijv. LHL) genoemd, die associëren met structurele posities in de metrische structuur, vandaar de naam autosegmenteel metrisch. Tonen zijn ofwel prominentiemarkerend en contrastief zoals wanneer gekoppeld aan een beklemtoonde syllabe (toon- 
hoogteaccent) of grens-markerend zoals wanneer gekoppeld aan de rand van de prosodische eenheid (frase-accent of grenstoon) (Jun, 2007). Metrische structuur beschrijft frasering (of de groepering van woorden) die voorkomt over kortere of langere eenheden (koppen en grenzen van constituenten):

(1) He thought of /Therese enjoying the burrito/ (Therese = enjoying burrito)

(2) He thought of Therese / enjoying the burrito/ (while enjoying the burrito)

Zoals in het bovenstaande voorbeeld wordt getoond, worden syntactische / semantische groeperingen gecued door prosodische fraseringen. Items binnen de intonatiefrase worden samen geïnterpreteerd, maar items over de frase worden dat niet. Frasering beïnvloedt ook de aanhechting van relatieve bijzinnen (relative clause; RC's) aan de zelfstandig naamwoordzinnen (noun phrase; NP's) in een uiting. Bijvoorbeeld in NP1 + NP2 + RC, kan RC hoog (wijziging NP1) of laag verbinden (wijzigen NP2) (Jun, 2003; Jun, 2007):

(1) Someone shot the servant (NP1) of the actress (NP2) who was on the balcony (RC) (Cuetos and Mitchell, 1988).

Sun (2007) wijst er verder op dat frasering ook de omvang bepaalt, zoals blijkt uit de volgende uitingen:

(1) John didn't hit Mary /because she was yelling (/ geeft pauze aan)

(2) John didn't hit Mary /w/ because she was yelling (/w/ geeft zwakke pauze aan)

Het werken aan het identificeren en / of voorspellen van de eenheden in prosodie evolueerde naar de segmentale verankeringhypothese (segmental anchoring hypothesis; SAH) oorspronkelijk bedacht door Arvaniti, Ladd en Mennen (1998). Het idee achter de SAH is dat zowel het begin als het einde van een stijgend toonhoogteaccent verankerd zijn aan specifieke oriëntatiepunten in de segmentstructuur, ongeacht de samenstelling van de segmentale of syllabestructuur, en ongeacht de spreeksnelheid (Prieto \& Torreira, 2007). Dit was in lijn met en hoogstwaarschijnlijk bevorderde perspectieven van akoestische gebaren in de fonologie van prosodische structuur die op dat moment begonnen. Binnen de articulatorische fonologie (bijv. Browman \& Goldstein 1986, 1992) zijn fonologie en fonetiek isomorf, en hun eenheden, gebaren genaamd, zijn fonologisch relevante gebeurtenissen van het spraakkanaal. Katsika, Krivokapic, Mooshammer, Tiede \& Goldstein (2014) geven een beschrijving van de drie soorten gebaren, namelijk constrictie, toon, en klok-vertragende gebaren, die in deze benadering worden gedefinieerd. Constrictiegebaren vormen of openen vernauwingen in het spraakkanaal. Ze zijn gespecificeerd voor abstracte talige taken (bijvoorbeeld lipsluiting voor $/ \mathrm{p} /$ ), en worden gerealiseerd door gecoördineerde acties van specifieke articulatoren (bijv. lippen en kaak voor de labiale sluiting in $/ p /$ ). Ze strekken uit in ruimte en tijd, en worden geactiveerd door interne oscillatoren. De oscillator die het begin van het consonantaal gebaar (C-gebaar) activeert, is in fase (synchroon) gecoördineerd met de oscillator die het kern-vocale gebaar (V-gebaar) activeert, en als resultaat wordt de beweging 
van de constrictor die de beginconsonant vormt synchroon geïnitieerd met de beweging van de constrictor die de kernklinker vormt. De oscillator die het coda C-gebaar activeert, daarentegen, is anti-fase (sequentieel) gecoördineerd met de oscillator die het V-gebaar initieert, en als gevolg daarvan wordt de beweging van de constrictor die de coda-consonant vormt geïnitieerd wanneer de beweging van de constrictor die de klinker vormt zijn doel bereikt (Katsika et al., 2014). Het is duidelijk dat deze twee soorten koppelingen de syllabische structuur kunnen verklaren. Toongebaren zijn vergelijkbaar met constrictiegebaren, echter, ze hebben betrekking op een andere reeks articulatoren dan de constrictiegebaren. Het doel van toongebaren is om talig relevante variaties te bereiken in de trillingsfrequentie van de stembanden (McGowan \& Saltzman, 1995; Fougeron \& Jun, 1998). Tenslotte verschillen klok-vertragende gebaren van constrictie- en toongebaren doordat ze niet gerelateerd zijn aan specifieke articulatoren. Hun voornaamste effect is het moduleren (verlengen en versterken) van spatiële en temporele eigenschappen van articulatorische gebaren die gelijktijdig daarmee actief zijn (bijv. Byrd \& Saltzman, 2003). Katsika et al. (2014), en anderen hebben aangetoond hoe articulatorische fonologie het mogelijk maakt vragen na te streven die duidelijk in de AM fonologie hadden kunnen worden gesteld. Deze onderzoekers stelden bijvoorbeeld de vraag hoe grenstonen worden gecoördineerd met constrictiegebaren en of prominentie (lexicale klemtoon) en / of frasering (toonhoogteaccent) deze coördinatie beïnvloedt.

Samenvattend kan worden geconcludeerd dat de huidige fonologische benaderingen van de prosodische structuur vooruitgang hebben geboekt met het definiëren van de locaties waar de toonkenmerken zijn gekoppeld aan bijvoorbeeld de rand van een fonologisch woord, een beklemtoonde (prominente) syllabe binnen het woord, of een frase-finale syllabe. Verder is er bewijs dat de prosodische structuur de timing en de grootte van articulatorische gebaren voor consonanten en klinkers beïnvloedt. In het algemeen gesproken is aangetoond dat gebaren worden verlengd en versterkt in bepaalde prosodische posities (bijvoorbeeld frase-initiaal en in prominente posities op fraseniveau), terwijl ze worden ingekort en gereduceerd in andere posities (frase-mediaal en in niet-prominente posities) (Byrd \& Saltzman,1998); Cho, 2005; Byrd, Krivokapic \& Lee, 2006; Cho \& Keating, 2009; Krivokapic \& Byrd, 2012). Deze effecten van prosodische context op articulatie geven aanleiding tot prosodisch geconditioneerde akoestische variatie in consonanten en klinkers (d.w.z. segmentale effecten), zoals gerapporteerd in talrijke studies gebaseerd op metingen van akoestische duur, klinkerformanten, voice onset time, intensiteit, en spectrale metingen van consonantplaats (Cho, 2005; Cole et al. 2007; Turk \& Shattuck-Hufnagel, 2007).

Terwijl intonatie-fonologische benaderingen van prosodie duidelijk floreerden, lieten (mislukte) pogingen om taalprosodie te classificeren in termen van ritme (isochronie) en / of consistent onderscheid te kunnen maken tussen syllabe-, klemtoon- of mora-getimede talen een aantal ritme-metrieken achter in het proces. Overeenkomend met het idee dat noch de syllabe noch de klemtoon met regelmatige tussenpozen werden getimed, observeerde Dauer (1983) dat verschillende fonologische eigenschappen de twee groepen talen onderscheiden. Hij merkte op dat 'syllabe-getimede' talen een kleinere verscheidenheid hebben 
aan syllabe types dan 'klemtoon-getimede' talen, en dat ze geen klinkerreductie vertonen. Deze twee kenmerken zijn verantwoordelijk voor het feit dat syllabes in syllabe-getimede talen meer op elkaar lijken qua duur, en helpen bij de perceptie van een staccato of een machinegeweer-effect ritme. In het Spaans en het Frans bestaan bijvoorbeeld meer dan de helft van de syllabes (per type frequentie) uit een consonant gevolgd door een klinker (CV) (Dauer 1983; Nespor, Shukla \& Mehler, 2011). Deze bevinding kwam neer op het stellen dat verschillende ritmes ontstaan als een 'gevolg' van een reeks onafhankelijke fonologische eigenschappen in plaats van dat een eenheid getimed of gecontroleerd wordt.

De ontdekking dat pasgeborenen in staat zijn om klemtoon-getimede talen te onderscheiden van lettergreep-getimede talen (Mehler et al. 1987; Mehler et al. 1988) gaf een nieuwe onderbouwing aan de realiteit dat kinderen reageren op een mogelijk verschil in deze talen. Ramus et al. (1999) dachten dat pasgeborenen in eerste instantie spraak beluisteren als een reeks klinkers die onderbroken worden door ruis (dat wil zeggen consonanten); deze hypothese staat bekend als de Time-Intensity Grid Representation (TIGRE; Mehler et al. 1996). Hiermee suggereerden ze dat de perceptie van verschillende ritmes wordt gecreëerd door de manier waarop klinkers worden afgewisseld met consonanten, maar ook door de manier waarop deze afwisseling wordt beïnvloed door klemtoongerelateerde variabiliteit in vocale intervallen zoals bepaald door beklemtoonde en onbeklemtoonde syllabes, voeten, en woorden (Nespor, Shukla \& Mehler, 2011). Dit idee is geformaliseerd in indexen, waaronder $\% \mathrm{~V}$ en $\Delta \mathrm{C}$. \% V verwijst naar de hoeveelheid tijd bezet door klinkers in de spraakstroom. Een hoog \%V impliceert dat het repertoire van de mogelijke typen syllabes beperkt is en dat bijgevolg de consonantintervallen niet veel variëren. $\Delta \mathrm{C}$ verwijst naar de standaarddeviaties van de duur van consonantintervallen. Het is duidelijk dat deze indexen geen verschillen in complexiteit van syllabenwisselingen vastleggen, zoals hieronder wordt weergegeven:

\section{$\mathrm{CCVCVCCCV}=\mathrm{CCCVCCVCV}==\mathrm{CCCVCVCCV}$}

Evenzo kan worden gezien dat deze metingen gevoelig zijn voor (variaties in) de spreeksnelheid. Deze beschouwingen werden in overweging genomen door Grabe \& Low (2002), die de paarsgewijze variabiliteitsindex (pairwise variability index; PVI) introduceerden, die kijkt naar de (lokale) variabiliteit in de duur van alle paren van vocale en intervocale intervallen. Grabe \& Low (2002) namen aan dat consonanten minder gevoelig zijn voor tempoveranderingen dan klinkers, en stelden daarom voor dat de ruwe (raw) meetwaarde rPVI wordt gebruikt om de variabiliteit in consonantale intervallen te meten, en dat de genormaliseerde maat nPVI wordt gebruikt om de variabiliteit in vocale intervallen te meten.

Rathcke \& Smith (2015) geven een vrij goede samenvatting van de stand van het debat tot nu toe over ritmisch onderzoek en taaltypologie wanneer ze stellen dat de mate waarin timingprocessen en fonologische structuur hand in hand gaan nog steeds tamelijk slecht wordt begrepen. Ze zijn het er echter wel mee eens dat er veel te zeggen is voor de suggestie van Nolan en Asu (2009) dat 'klemtoon-timing' en 'syllabe-timing' kunnen functi- 
oneren als orthogonale variabelen van linguïstisch ritme, en naast elkaar bestaan op verschillende niveaus van prosodisch structuur in dezelfde taal. Er bestaat ook consensus dat ritme-metrieken erg gevoelig zijn voor de effecten die methodologische keuzes hebben op het meten van de duur van consonantale en vocale intervallen. In feite hebben verschillende studies zich gericht op het documenteren van juist deze methodologische keuzes. Wiget et al. (2010) vonden dat de variabiliteit in de metrische scores van individuele zinnen van het Engels groter was dan zowel de verschillen als gevolg van segmentatie-aanpakken door annotatoren als door inter-spreker variaties. Verder vonden ze dat spontane spraak variabeler is in zijn timingpatronen in vergelijking met lezen, en dat sprekers aanzienlijk van elkaar verschillen, mogelijk vanwege keuzes zoals spreeksnelheid en de helderheid van hun spraak (die de mate van klinkerreducties en de duur van consonantclusters zou kunnen beïnvloeden). Ze concluderen dat het niet raadzaam is om metrische scores te vergelijken tussen studies, metrieken en talen.

\section{Prosodische metrieken in motorische spraakstoornissen}

In de afgelopen jaren is er steeds meer bewijs voor het idee dat temporele prosodie in spraakapraxie een onderscheidend kenmerk is voor differentiaaldiagnose (Haley, Jacks, de Riesthal, Abou-Khalil, \& Roth, 2012; Haley et al., 2012; Murray, McCabe, Heard \& Ballard, 2015; Virgis, Ballard, Duffy, McNeill, Scholl \& Layfield, 2014), en dat vooral de paarsgewijze variabiliteitsindex van klinkerduur nuttig is om individuen met spraakapraxie plus afasie te differentiëren van mensen met alleen afasie en van gezonde controles (Vergis et al., 2014). Geautomatiseerde softwareroutines zijn ontwikkeld die klinkerkernen identificeren en data invoer voor het algoritme vergemakkelijken (de Jong \& Wempe, 2009; Shahin, Ahmed \& Ballard, 2012; Vogel, Shirbin, Churchyard, \& Stout, 2012). Verder hebben verschillende studies significante correlaties aangetoond tussen perceptuele beoordelingen en akoestische metingen van prosodie. Haley et al., (2012) rapporteren bijvoorbeeld dat de meting van syllabeduur in zinnen sterk correleerde met beoordelingen van globale prosodie (0.78), trage spreeksnelheid (0.75) en beperkt toonhoogtebereik (0.73). Ballard, Robin, McCabe \& McDonald (2010) laten zien dat de paarsgewijze variabiliteitsindex van klinkerduur in multisyllabische woorden sterk correleerde met beoordelingen van 'goedheid' van het geproduceerde klemtoonpatroon (0.80-0.91). Het bewijs voor de dysartrieën is wisselend. Liss et al., (2009) hebben verschillende ritme-indices gebruikt, waaronder $\Delta \mathrm{V}, \Delta \mathrm{C}, \% \mathrm{~V}$, VarcoV, VarcoC, nPVI-V en rPVI-C, en vonden dat verschillende combinaties daarvan redelijkerwijs de dysartrieën van elkaar en van normaal gezonde sprekers kunnen onderscheiden. Lowit (2014) rapporteerde echter dat geen van de metrieken dit kon doen, ondanks duidelijke perceptuele verschillen.

\section{Conclusie}

Prosodie en motorische spraakstoornissen kruisten elkaar in de vroege jaren tachtig in Kent \& Rosenbek (1983). In recentere jaren lijkt het alsof er een serieuzere samensmelting plaats- 
vindt waarbij de toepassing van ritme-indices vaste vormen aanneemt, en de differentiële classificatie van motorische spraakstoornissen, die eens volledig geworteld was in de audioperceptuele methode, aanvullen. Toch blijven er methodologische problemen bestaan die de toepassing grotendeels belemmeren in het domein van de classificatie van dysartrie. Verder hebben ritme-indices nog steeds te kampen met een gebrek aan een referentieprobleem, omdat ze momenteel worden toegepast zonder veel begeleiding of consistentie als het gaat om prosodische eenheden die zijn geïdentificeerd in talige prosodiebenaderingen. Bovendien, terwijl ritme-indices variabiliteit van duur kwantificeren in prosodie, wachten de dimensies van intensiteit en toonhoogte nog steeds op beoordeling.

\section{Referenties}

Abercrombie, D. (1967). Elements of general phonetics. Edinburgh University Press, Edinburgh.

Arvaniti, A. 2011. The representation of intonation. In M. van Oostendorp, C. Ewen, E. Hume and K. Rice (Eds): Companion to Phonology, Wiley-Blackwell.

Arvaniti, A., Ladd, D.R. \& Mennen, I. (1998). Stability of tonal alignment: the case of Greek prenuclear accents. Journal of Phonetics, 26, 3-25.

Ballard, K. J., Robin, D. A., McCabe, P., \& McDonald, J. (2010). A treatment for dysprosody in childhood apraxia of speech. Journal of Speech, Language, and Hearing Research, $53,1227-1245$.

Beckman, M. \& Pierrehumbert, J. (1986). Intonational structure in Japanese and English. Phonology Yearbook, 3, 255-309.

Boutsen, F., \& Christman, S. (2002) Prosody in apraxia of speech. Seminars in Speech and Language 23, 245-256.

Boutsen, F. (2003). Prosody: The music of language and speech. ASHA Leader, 5, 7-9.

Boutsen, F. (2004). Aprosody: A right hemisphere dysarthria. Journal of Medical SpeechLanguage Pathology, 12, 67-76.

Boutsen, F. (2006). Dysarthria: Motor speech processes. In K. Brown (Ed.): The encyclopedia of language and linguistics (2nd ed), London: Elsevier, pp. 482-485.

Boutsen, F. (2008). Prosody: An organizing principle for neurogenic speech disorders. Asian Pacific Journal of Speech, Language, and Hearing, 11, 81-87.

Boutsen, F. (2010). Speech processes in dysarthria. In H. A. Whitaker (Ed.): Concise encyclopedia of brain and language, Elsevier.

Bloomfield, L. (1935). Language. London: George Allen \& Unwin.

Bolinger, D. (1958). A theory of pitch accent in English. Word, 14, 109-149.

Bolinger, D. (1965). Pitch accent and sentence rhythm, Forms of English: Accent, morpheme, order. Cambridge, MA: Harvard University Press.

Browman, C., \& Goldstein, L. (1986) Towards an Articulatory Phonology. Phonology Yearbook, 3, 219-252.

Browman, C., \& Goldstein, L. (1992) Articulatory Phonology: An overview. Phonetica, 45,155180. 
Byrd, D., \& Saltzman, E. (2003). The elastic phrase: Modeling the dynamics of boundaryadjacent lengthening. Journal of Phonetics, 31, 149-180.

Byrd, D., Krivokapic, J., \& Lee, S. (2006). How far, how long: On the temporal scope of phrase boundary effects. Journal of the Acoustical Society of America, 120, 1589-1599.

Cho, T. (2005). Prosodic strengthening and featural enhancement: Evidence from acoustic and articulatory realizations of /a, i/ in English. Journal of the Acoustical Society of America, 117, 3867-3878.

Cho, T., \& Keating, P. (2009). Effects of initial position versus prominence in English. Journal of Phonetics, 37, 466-485.

Cuetos, F., \& Mitchell, D. (1988). Cross-linguistic differences in parsing: Restrictions on the use of the late closure strategy in Spanish. Cognition, 30, 72-105.

Darley, F., Aronson, A.E, Brown, J.R (1969a). Differential diagnostic patterns of dysarthria, Journal of Speech and Hearing Research, 12, 249-269.

Darley, F., Aronson, A.E, Brown, J.R (1969b). Clusters of deviant dimensions in the dysarthrias. Journal of Speech and Hearing Research, 12, 462-696.

Darley, F., Aronson, A.E, Brown, J.R. (1975). Motor speech disorders. Philadelphia: W.B. Saunders.

Dauer, Rebecca M. 1983. Stress-timing and syllable-timing reanalyzed. Journal of Phonetics, 11. 51-62.

Duffy, J. R. (1995). Motor speech disorders: Substrates, differential diagnosis, and management. St. Louis, MO: Mosby-Year Book.

Fougeron, C. \& Jun, S. 1998. Rate Effects on French Intonation: Phonetic Realization and Prosodic Organization. Journal of Phonetics, 26, 45-70.

Fox, A. (2002). Prosodic Features and Prosodic Structure. The Phonology of Suprasegmentals. Oxford University Press.

Froeshels, E. (1943). A contribution of the pathology and therapy due to certain cerebral lesions. Journal of Speech Disorders, 1943, 8, 301-321.

Fry, D. 1955. Duration and intensity as physical correlates of linguistic stress. Journal of Acoustical Society of America, 23, 765-769.

Gibbon, D. (1976). Perspectives of intonation analysis. Forum linguisticus, Band 9. Bern: Herbert Lang.

Grabe, E and Low, L 2002. Durational variability in speech and the rhythm class hypothesis. In Carlos Gussenhoven \& Natasha Warner (eds.): Laboratory phonology 7. 377-401. Berlin \& New York: Mouton de Gruyter.

Grewel, F.(1957). Classification of Dysarthrias. Acta Psychiatrica Scandinavica, 32, 325-337.

Haley, K., Jacks, A., de Riesthal, M., Abou-Khalil, R., \& Roth, H. (2012). Toward a quantitative basis for assessment and diagnosis of AOS. Journal of Speech, Language, and Hearing Research, 55, S1502-S1517.

Jakobson, R. (1931) Die Betonung und Ihre Rolle in der Wort- und Syntagmaphonologie, Travaux du Cercle linguistique de Prague, 4,164-182.

Jakobson, R., Fant, G., \& Halle, M. (1951). Preliminaries to speech analysis: The distinctive features and their correlates. Cambridge, MA: MIT Press.

Jong N.H. de \& Wempe T. (2009), Praat script to detect syllable nuclei and measure speech 
rate automatically, Behavior Research Methods 41, 385-390

Jun, S-A. (2003). Prosodic Phrasing and Attachment Preferences. Journal of Psycholinguistic Research, 32, 2, 219-249.

Jun, S-A. \& Bishop, J. (2014). Implicit prosodic priming and autistic traits in relative clause attachment. In. Campbell, Gibbon, \& Hirst (Eds.): Proceedings of Speech Prosody XII, pp. 854 - 857.

Jun, S-A. (2007). Defining and Explaining Prosodic Phrasing: An Overview. Workshop on Prosody, Syntax, and Information Structure 3, Sept. 14-15, Indiana University,

Katsika, A., Krivokapic, J., Mooshammer , C., Tiede, M., \& Goldstein, L. M. (2014). The coordination of boundary tones and their interaction with prominence. Journal of Phonetics, 44, 62-82.

Kent and Netsell Kent, R.D., \& Netsell, R. (1975). A case study of an ataxic dysarthric: cineradiographic and spectrographic observations. The Journal of Speech and Hearing Disorders, 40, 115-134.

Krivokapic , J., \& Byrd, D. (2012). Prosodic boundary strength: An articulatory and perceptual study. Journal of Phonetics, 40, 430-442.

Kusmaul, A. (1877). Die storungen der sprache. Leipzig. F.C.W. Vogel, 1877

Ladefoged, P., \& Mckinney, N. (1963) Loudness, Sound Pressure, and Subglottal Pressure in Speech. The Journal of the Acoustical Society of America, 35, 454-460.

Ladd, D.R. (1996). Intonational Phonology. Cambridge: Cambridge University Press.

Lieberman, P. (1967). Intonation, Perception and Language. Cambridge, Mass.: MIT Press.

Liss, J. M., White, L., Mattys, S. L., Lansford, K., Spitzer, S., Lotto, A. J., \& Caviness, J. N. (2009). Quantifying speech rhythm deficits in the dysarthrias. Journal of Speech, Language, and Hearing Research, 52, 1334-1352.

Lowit, A . (2014) Quantification of rhythm problems in disordered speech: a re-evaluation. Phil. Trans. R. Soc. B 369, 20130404.

Luchsinger, R., and Arnold, G.E. (1949). Lehrbuch der Stimm-und Sprachheilkunde. Vienna: Springer -Verlag.

McGowan, R, Saltzman E (1995). Incorporating aerodynamic and laryngeal components into task dynamics. Journal of Phonetics, 23, 255-269.

McNeil, M. (1997) Clinical Management of Sensorimotor Speech Disorders. Thieme: Stuttgart. Marie, P. and Foix, C. (1917) Les aphasies de guerre. Rev. neurol., 24, 53-87.

Mehler, Jacques, Emmanuel Dupoux, Thierry Nazzi \& Ghislaine Dehaene-Lambertz, G. 1996. Coping with linguistic diversity: The infant's viewpoint. In Morgan \& Demuth (1996), 101-116.

Mehler, Jacques, Peter Jusczyk, Ghislaine Lambertz, Nilofar Halsted, Josiane Bertoncini \& Claudine Amiel-Tison. 1988. A precursor of language acquisition in young infants. Cognition, 29, 143-178.

Monrad Krohn, G. H. (1948). Dysprosdy or altered 'melody of language'. Brain, 70, 405-415.

Nespor, I. \& Vogel, I. (1986) Prosodic Phonology. Foris: Dordrecht.

Nespor, M., Shukla, M., \& Mehler, J. (2011). Stress-timed vs.syllable-timed languages. Blackwell. Comp. Phonol., 1147-1159.

Nolan, F., and Asu, E. (2009). The pairwise variability index and co-existing rhythms in 


\section{PROSODIE EN MOTORISCHE SPRAAKSTOORNISSEN: HISTORISCH OVERZICHT 115}

language, Phonetica, 66, 64-77.

Peacher, W.G. (1950) The etiology and differntial diagnosis of dysarthria. Journal of Speech and Hearing Disorders, 15, 252-265.

Pierre Marie (1906). La Semaine medicale, xxvi, 241.

Pierrehumbert, J. (1980). The phonology and phonetics of English intonation (Doctoral Dissertation). Cambridge, MA: Massachusetts Institute of Technology. Distributed by the Indiana University Linguistics Club (1988).

Pierrehumbert, J., \& Beckman, M. (1988). Japanese tone structure. Cambridge, MA: MIT Press

Prieto, P, \& Torreira, F. (2007) The segmental anchoring hypothesis revisited. Syllable structure and speech rate effects on peak timing in Spanish. Journal of Phonetics, 35, 473500.

Prince, A. and Smolensky, P. (1993) Optimality Theory: Constraint interaction in generative grammar. Technical Report CU-CS-696-93, Department of Computer Science, University of Colorado at Boulder, and Technical Report TR-2, Rutgers Center for Cognitive Science, Rutgers University, New Brunswick, N.J. April.

Ross, E. and Mesulam, M. (1979) Dominant Language Functions of the Right Hemisphere? Prosody and Emotional Gesturing. Archives of Neurology, 36, 144-148.

Rathcke, T. and Smith, R. (2015). Speech Timing and Linguistic Rhythm: On the Acoustic Bases of Rhythm Typologies. The Journal of the Acoustical Society of America, 137, 2834-2845

Selkirk, E. (1981). On prosodic structure and its relation to syntactic structure. In Nordic Phonology II, ed. Thorstein Fretheim, 111-140. Trondheim: Tapir.

Shahin M.A., Ahmed B., Ballard K.J. (2012) Automatic classification of unequal lexical stress patterns using machine learning algorithms. Miami, FL USA. pp. 388-391.

Shattuck-Hufnagel, S. and Turk, A. (1996). Prosody Tutorial for Investigators of Auditory Sentence Processing, Journal of Psycholinguistic Research, 25, 193-245

Tilsen, S. \& Johnson, K. (2008) Low-frequency Fourier analysis of speech rhythm. Journal of the Acoustical Society of America, 124, 2, EL34-39.

Trubetzkoy, N. (1939). Grundzuge der Phonologie. Prague: Cercle Linguistique du Prague.

Van der Merwe, A. (1997). A theoretical framework for the characterization of Pathological Speech Sensori Motor Control. In M. McNeil (Ed.) Clinical Management of Sensorimotor speech disorders. Thieme: Stuttgart. pp.1-25

Vanderslice, R. (1969). Intonation, Scientism, and Archetypality. Studies in Language and Language Behavior, Progress Report VIII, 429-436

Virgis, M., Ballard, K., Duffy, J. McNeill, M., Scholl D., and Layfield, C. (2014). An acoustic measure of lexical stress differentiates aphasia and aphasia plus apraxia of speech after stroke. Aphasiology, 28, 554-575.

Vogel, A., Shirbin, C., Churchyard., A \& Stout, J. (2012). Speech acoustic markers of early stage and prodromal Huntington's Disease: a marker of disease onset? Neuropsychologia, 50, 3273-3278.

Wiget, L., White, L., Schuppler, B., Grenon, I., Rauch, O., and Mattys, S. 2010. How stable are acoustic metrics of contrastive speech rhythm? The Journal of the Acoustical Society of 
America, 127, 1559-1569.

Xu, Y. (2011). Speech prosody: A methodological review. Journal of Speech Sciences, 1, 85115.

$\mathrm{Xu}, \mathrm{Y}$. (2015). Speech Prosody - Theories, models and analysis. In Courses on Speech Prosody. A. R. Meireles (ed.): Cambridge Scholars Publishing. pp. 146-177.

Zentay, P.J. (1937) Motor disorders of the central nervous system and their significance for speech. Journal of Speech Disorders, 2, 131-138. 